\title{
COST Action IS1102. La reestructuració dels serveis socials a Europa conseqüències de la crisi econòmica
}

\author{
Blanca Deusdad
}

La nova situació de crisi financera mundial ha comportat una crisi de les estructures dels estats del benestar europeus. Des de la dècada dels anys vuitanta amb les polítiques neoliberals s'ha estat produint una reestructuració del serveis socials en els països europeus, els quals s'havien desenvolupament des de la fi de la Segona Guerra Mundial. En el marc d'aquest context social va néixer el projecte COST Action IS1102, Social Services, Welfare State and Places. The restructuring of social services in Europe and its impacts on social and territorial cohesion and governance.

El projecte té com a objectiu conèixer en profunditat la provisió de serveis socials, a través d'una anàlisi comparativa entre els països participants. A la vegada, intenta difondre la tasca de recerca entre els actors locals i crear una xarxa. El projecte està liderat i dirigit per la Prof. Flavia Martinelli, de la Università degli Studi Mediterranea di Reggio Calabria, i hi participen universitats de 19 països europeus; recentment, s'hi ha incorporat una universitat d'Argentina i una altra d'Israel.

Els projectes COST s'iniciaren el 1971 al si del Consell de la Unió Europea. Actualment engloben projectes de recerca de diversos àmbits científics, concretament fins a 9 dominis. El projecte que presentem està inclòs en el domini d'Individus, Societats, Cultures i Salut (ISCH), el qual té quatre grups temàtics dels àmbits següents: Salut, Educació i Desenvolupament Individual, on pertany el projecte que presentem; Ciència, Economia, Tecnologia i Mitjans; Llei, Polítiques i Governança, i Història i Identitat. Dins el marc d'aquests projectes es contempla la possibilitat d'organitzar congressos, seminaris i jornades; reunions del comitè científic, estades curtes per a joves investigadors, escoles de formació i diferents estratègies de disseminació de resultats.

Lobjectiu principal del projecte és analitzar la reestructuració dels serveis socials als diferents països participants tant en l'àmbit local com regional i estatal a partir de cinc perspectives: 
- Leficiència en els costos mesurada a través de la qualitat dels serveis i la satisfacció dels usuaris.

- Governança democràtica. La subsidiarietat tant de forma vertical — participació de les diferents administracions polítiques - com de forma horitzontal — diversitat de proveïdors-.

- Cohesió social i territorial. La reestructuració dels serveis socials ha comportat la discriminació social i també les desigualtats territorials i un accés no universal als serveis.

- Mercat laboral. La qualitat dels serveis depèn molt de la professionalització o formació dels treballadors. La desregulació del mercat laboral afecta també aquest sector, que s'ha privatitzat i ofereix una pluralitat de serveis.

- Igualtat d’oportunitats i gènere. El procés de reestructuració dels serveis socials comporta desigualtats d'oportunitats, la qual cosa afecta les dones com a proveïdores i usuàries de serveis socials i també altres col-lectius vulnerables, com la joventut i la immigració.

El projecte es troba en el seu segon any, es va iniciar al novembre del 2011 i té previst finalitzar el 2015. L'Acció es reestructura en 4 grups de treball amb tasques diferenciades i amb una temporalització precisa. El Grup de Treball 1 s'ha desenvolupat durant el primer any de l'acció i va centrar la seva feina en l'elaboració de documents comparatius sobre les diferents estructures dels serveis socials i d'atenció i cura a les persones. Aquests documents es van elaborar sobre la majoria dels països participants.

En aquests moments es duu a terme el Grup de Treball 2, el qual té previst desenvolupar diferents estudis de cas sobre els canvis que sestan produint a Europa en l'àmbit dels serveis socials i que afecten colllectius més vulnerables i el benestar general de la població. Els eixos temàtics són: gent gran i persones amb discapacitat; infancia; assistència social; habitatge i barris, i serveis socials d'interès general. El Grup de Treball 3 es començarà el darrer any i es basarà en l'anàlisi de bones i males pràctiques, orientat a assessorar i influir en polítiques socials. El Grup de Treball 4 es basa en la difusió de resultats, a través de publicacions, i la capacitat de crear xarxes d'actors locals.

Durant el primer any (2012), s'han dut a terme 3 jornades en què s'han publicat diferents documents científics. El primer document comparatiu presentat per cada país va consistir en l'estructura estatal/regional dels serveis so- 
cials. Un segon document va consistir en una anàlisi detallada per països d'un dels diferents àmbits analitzats prèviament (atenció i cura a la infància, la gent gran i diversitat funcional, i assistència social). El tercer grup de documents és el resultat obtingut a partir de l'anàlisi i lectura transversal o comparativa dels diferents documents presentats fins aleshores. ${ }^{1}$

Una de les jornades es va celebrar a Tarragona, al Departament d'Antropologia, Filosofia i Treball Social de la URV, amb la participació d'investigadors/es de més de 15 països. Les jornades van portar per títol "Els serveis socials i la crisi a Espanya”. El primer dia es va dedicar a donar a conèixer a través de la participació de diferents experts i analistes la situació dels serveis socials davant la crisi. La sessió del matí es va centrar en els serveis socials i més específicament en el cas del País Basc i Catalunya; la de la tarda va consistir en el coneixement de la tasca del tercer sector davant la crisi. Ambdues sessions van anar seguides d'intervencions d'experts del projecte COST, que van aportar elements per a la discussió. La resta de dies va consistir en l'exposició per països dels diferents àmbits dels serveis socials tractats i una reunió del Comitè de Gestió i una altra del Comitè de Direcció.

Les altres jornades, en el marc del Grup de Treball 1, es van celebrar a la Universitat d'Oslo i Akershus i a la Universitat Catòlica Portuguesa de Porto. Durant el 2013, hi ha previstes dues jornades més: una a la Universitat d'Islàndia i l'altra a la Universitat de Galati, a Romania. Ambdues jornades consistiran en la presentació dels resultats de les recerques que es duen a terme en el marc del Grup de Treball 2.

En el cas de les investigadores de l'àrea de Treball Social de la URV, es va liderar el Grup de Treball 1 i es van presentar documents sobre l'estructura dels serveis socials i el desenvolupament i la cura a la infancia $i$ a les persones grans a Espanya i Catalunya. ${ }^{2}$ Actualment, realitzem un estudi de cas sobre la gent gran a la ciutat de Tarragona que té com a objectiu analitzar els aspectes que hem comentat i que figuren com a part del Grup de Treball 2. ${ }^{3}$ La recerca es troba en una fase inicial, però ens permetrà fer una anàlisi comparativa amb

\footnotetext{
1 Aquests documents seran accessibles en breu des del web de l'acció (<http://www.cost-is1102-cohesion. unirc.it $>$ ) en un format DOI. Al web també s'hi especifica detalladament el projecte COST.

2 Blanca Deusdad, de la URV, ha liderat el Grup de Treball 1 del projecte i el document serà publicat junt amb la resta de documents en breu.

3 Com a investigadora de l’àrea de Treball Social, també s'ha incorporat Eva Zafra al Grup de Treball 2.
} 
altres països europeus sobre els diferents models d'Estat del benestar i perfilar les tendències i les conseqüències de la crisi financera als diferents països europeus.

La xarxa d'investigadors del projecte, com he exposat més amunt, és àmplia i això requereix tenir en compte, si bé no una mateixa metodologia de treball, sí uns mateixos paràmetres comparatius i temàtics. Durant el primer any, els documents estàndards elaborats han servit també per conèixer la tasca dels membres del grup i generar dinàmiques de treball comunes. La complexitat de l'estructura fa que hi hagi un treball constant per part de la directora del projecte i també dels líders i colíders dels grups en aspectes propis de la gestió de la recerca, en la celebració de les diferents jornades i en aspectes formals del Comitè de Gestió, on també està representada la Universitat Rovira i Virgili. ${ }^{4}$ Amb tot, la dinàmica del grup sembla haver-se consolidat i el tarannà $i$ bona entesa entre tots fa que sigui cada cop més facil i agradable treballar plegats.

L'agreujament de la situació financera mundial i les importants retallades efectuades pels estats europeus notablement afectats per la crisi ha comportat un accelerament del procés que tot just es començava a analitzar. La rapidesa i la gravetat dels esdeveniments arran de la crisi financera mundial ha fet que el que es preveia com una tendència per analitzar s'hagi convertit de forma molt ràpida en una situació alarmant que ha accelerat l'estudi de certs aspectes. Amb això vull fer referència a la pèrdua greu de drets socials i serveis públics als països del sud d'Europa afectats per la crisi d'una forma més crítica, on s'inclouria també Irlanda i la Gran Bretanya. Aquestes retallades socials poden tenir conseqüències irreversibles per a la població i posen en qüestió la persistència dels estats del benestar europeus, els quals havien aconseguit garantir unes condicions de vida dignes i de qualitat per a la població.

En el cas d'Espanya i Catalunya, durant el franquisme hi havia un model assistencial, subsidiari, basat en la caritat. A partir de la dècada de 1980, ja amb la consolidació democràtica, es creen els serveis socials descentralitzats en les distintes comunitats autònomes, en un procés que tendia cap a la universalització de serveis. Aquest és el cas de la sanitat, també, i ja durant la dècada de 2000 es promulga la llei coneguda popularment com de dependència o LAPAD, que

4 Des de l'àrea de Treball Social del Departament d'Antropologia, Filosofia i Treball Social de la URV, Blanca Deusdad participa com a representant d'Espanya al Comitè de Gestió; l'altre representant d'Espanya és Marisol García, de la Universitat de Barcelona. 
té com objectiu l'atenció a les persones en situació de dependència, tant si és com a conseqüència de l'envelliment com per tenir una diversitat funcional. ${ }^{5} \mathrm{La}$ situació és molt similar a països com Grècia i Portugal, i també a Itàlia, on els serveis s'estructuren també regionalment.

Aquests avenços socials representaven un intent d'apropar-nos als nivells de benestar aconseguits pels països nòrdics. Com a conseqüència de la crisi i de l'aplicació de les mesures neoliberals, l'universalisme en què ens emmirallaven i era reivindicat com a objectiu per assolir, sobretot per a les dones i els joves, es veu fins i tot qüestionat des d'un punt de vista ètic. L'estat del benestar es considera una forma paternalista d'entendre els serveis el qual limita la necessitat de posar l'accent en la responsabilitat dels usuaris.

Amb els darrers decrets 2011 i 2012 i les mesures pressupostàries adoptades s'ha produit un important retrocés en els drets socials i la sanitat ha deixat de ser universal. ${ }^{6}$ Així, doncs, d'un model universal amb aspectes residuals i de selectivisme on les administracions garantien uns drets socials i subjectius, s'ha passat a una situació d'augment de l'assistencialisme i la subsidiarietat on les organitzacions del tercer sector, algunes amb un clar perfil caritatiu, estan tenint un pes molt important per afrontar la crisi (Deusdad, 2012, 2013).

En el cas de Grècia, està tenint també un pes molt important en l'atenció a la gent gran els voluntaris pertanyents a l'Església ortodoxa grega, alhora que s'ha produit un augment de la privatització de l'atenció a la gent gran des de la dècada de 1980 (Vaio, 2012). En el cas d'Itàlia, destaca que s'han reduït les hores d'atenció en el serveis d'informació i hi ha hagut un augment de les llistes

5 En l'àmbit de la sanitat, la Llei 14/1986, de 25 d'abril, general de sanitat va permetre l'assistència sanitària universal i la Llei estatal 39/2006, de 14 de desembre, de promoció de l'autonomia personal i atenció a les persones en situació de dependència (LAPAD) permet les ajudes a les persones segons el seu grau de dependència i contempla la remuneració de la cura informal.

6 Destacarem alguns dels decrets més importants que han implicat canvis importants en matèria de benestar social. El Real Decreto-ley 20/2011, de 30 de diciembre, de medidas urgentes en materia presupuestaria, tributaria y financiera para la corrección del déficit público. El decret que ha significat un retrocés més important és el Real Decreto-ley 16/2012, de 20 de abril, de medidas urgentes para garantizar la sostenibilidad del Sistema Nacional de Salud y mejorar la calidad y seguridad de sus prestaciones, que ha comportat la pèrdua de la sanitat universal i que depengui de la seguretat social. No podran, per tant, gaudir de la sanitat gratuïta els majors de 26 anys que no hagin cotitzat mai a la seguretat social; les persones no residents de la UE i Suïssa, i, només en cas d'urgència, les persones no extracomunitàries, exceptuant el cas de les dones embarassades. Cal afegir en matèria de sanitat el Decreto Ley de reforma sanitaria que establece el copago farmacéutico, que estableix el copagament dels farmacs. També cal destacar el Real Decreto-ley 20/2012, de 13 de julio, de medidas para garantizar la estabilidad presupuestaria y de fomento de la competitividad, a través del qual es limita l'aplicació de la LAPAD. 
d'espera en residències i també per rebre les prestacions, la qual cosa també succeeix en el cas d'Espanya (Martinelli, 2012).

En el cas dels països nòrdics, hi ha també un procés de reestructuració $\mathrm{i}$ sobserva en països com Finlàndia una tendència cap a la mercantilització amb processos de subcontractació, concursos públics, sistema de bonificacions i un augment de la cura informal, alhora que es posa èmfasi en les responsabilitats familiars, que s'han convertit ara en una obligació. Així, doncs, sespera que siguin les famílies qui hi donin resposta, mentre que abans l'Estat tenia un paper més important de suport i ajuda (Anttonen i Häiklö, 2011). A la vegada, l'augment de les despeses en serveis de cura i atenció ha comportat un augment de la cura informal sense que sigui reconeguda (Leinonen, Sihto i Kröger, 2012).

En els països del sud d'Europa com Itàlia, Espanya o Grècia i en països nòrdics com Finlàndia s'hi observen desigualtats territorials. Els serveis que sofereixen depenen de les administracions municipals i varien segons els municipis. El criteri per a aquesta diversitat d'ofertes no respon a les necessitats de la població o a les seves habilitats funcionals, sinó que es fa en funció de criteris de distribució dels recursos o de les finances dels ajuntaments.

Els aspectes referents al gènere també es veuen afectats, el serveis socials han significat una important font per introduir una gran quantitat de dones al mercat laboral (Anttonen i Sipilä, 1996). Amb la situació de crisi econòmica en països com Espanya, les dones ja no són necessàries per al mercat laboral com a força de treball i són altre cop forçades a adoptar estratègies d’ajuda a la família com la cura informal i altres necessitats.

En la recerca que sestà duent a terme fins ara, es perfilen diferències sobretot nord-sud entre els països europeus. Aquests eixos es prenen com a diferenciadors socioeconòmics entre aquells països on, tot i la reestructuració, persisteixen serveis i recursos en l'àmbit de la cura i atenció a les persones $i$ recursos assistencials $i$ aquells on, arran de la crisi, hi ha fortes mancances $i$ s'accentuen situacions de pobresa i vulnerabilitat. La crisi econòmica en els països més afectats està perfilant una societat dual amb una tendència que deriva cap a l'americanització de la societat. Un sector de la població està cada cop més empobrit i la manca de provisió de serveis públics fa emergir amb més força el tercer sector, com a garant de situacions d'emergència i pobresa. 
El projecte, com he exposat, es troba en procés de desenvolupament. Tanmateix, la importància i la magnitud de la transformació dels serveis socials europeus, com a conseqüència de la crisi econòmica i les mesures polítiques i econòmiques adoptades, fa que la recerca aporti resultats nous i crucials per poder analitzar els fenòmens de canvi social que sestan produint i la gravetat $i$ transcendència de les mesures i tendències adoptades.

\section{Referències}

Anttonen, A.; Häıniö, L.; Stefánsson, K. (2012). Welfare State, Universalism and Diversity. Cheltenham: Edward Elgar.

Anttonen, A.; Häikiö, L. (2011). "Care «going market»: Finish Elderly-care policies in transition", Nordic Journal of Social Research 2:1-21 Anttonen, A.; Sipilä, J. (1996). "European Social Care Services. Is it possible to identify models?", Journal of European Social Policy 6 (2): 87-100.

Deusdad, B. (2012). Spanish profile and the regional profile of Catalonia. Universitat Rovira i Virgili. Oslo Workshop, 18-19 June 2012.

- (2013). Universalism or Subsidiarity in Social Care for Older People from a Gender

Perspective. Universitat Rovira i Virgili. Porto Workshop, 18-21 February 2013.

Leinonen, E;; Sinto, T,; KRöger, T. (2012). Current organisational framework of care services for older people in Finland. University of Jyväskylä. Tarragona Workshop, 17-19 October 2012.

Martinelli, F. (2012). Current organisational framework of elderly care services in Italy. Università Mediterranea di Reggio Calabria. Tarragona Workshop, 17-19 October 2012.

VAio, D. (2012). Current organisational framework of elderly care services in Greece. National Technical University of Athens. Tarragona Workshop, 17-19 October 2012. 